\title{
A Utilização de Ferramentas de Análise de Vínculos no Combate aos Crimes de Lavagem DE ATIvos
}

CIDE FERREIRA ROMÃO

Departamento de Polícia Federal - Brasil

$$
\text { ○浆方 }
$$

\section{RESUMO}

O objetivo do presente trabalho é abordar as técnicas de investigação dos crimes de lavagem de ativos, com ênfase na utilização das ferramentas de análise de vínculos (link analysis). Estas ferramentas desempenham papel preponderante na identificação e consequente demonstração dos relacionamentos existentes entre os diversos atores envolvidos nos crimes de lavagem de dinheiro, permitindo a visualização e o entendimento das estruturas das organizaçôes criminosas investigadas.

Palavras-Chave: Análise de vínculos. Lavagem de dinheiro. Investigação Criminal.

\section{INTRODUÇÃ̃o}

Uma das grandes preocupações no cenário do combate ao crime organizado é o combate à lavagem de dinheiro. A transnacionalidade destes grupos facilita uma gama de contatos e redes de relacionamentos em diversos países do mundo, facilitando a movimentação dos ativos.

A definição de lavagem de dinheiro segundo o Grupo de Ação Financeira sobre Lavagem de Dinheiro (GAFI/FATF) é "a utilização e transformação de produtos do crime para dissimular a sua origem ilícita, com o objetivo de legitimar os proventos resultantes da atividade criminosa" (SNSP/MJ1, 2011, p. 9)ํ․ Decorrente dessas preocupações, os países signatários das Convenções de Viena e de Palermo buscam adotar medidas para dificultar essas ações e/ou realizar investigações que permitam a localização e retorno do capital fruto de atos ilícitos.

1 A sigla SNSP/MJ refere-se à Secretaria Nacional de Segurança Pública do Ministério da Justiça, promotora do curso de combate à lavagem de dinheiro, em 2011. Doravante, todas as citaçóes extraídas dos módulos 1 e 2 do referido curso, serão referenciadas por esta sigla, seguida do número do módulo, ano e página. 
O objetivo do presente é contribuir com a formatação de metodologias de investigação policial, buscando a celeridade e a eficácia na formação do escopo probatório na investigação de crimes financeiros.

Mas como obter celeridade e eficácia na investigação de crimes que muitas vezes decorrem de outros antecedentes de grande complexidade, como por exemplo, a corrupção de agentes públicos e políticos, tráfico de armas e de drogas, contrabando e financiamento ao terrorismo? - Por meio do desenvolvimento e/ou aperfeiçoamento de metodologias de utilização das ferramentas de análise de vínculo, tomando como exemplo a suíte de softwares "I2", utilizadas na investigação desses crimes pelo Departamento de Polícia Federal.

Por sua vez, o combate à criminalidade organizada é uma preocupação mundial, demandando esforços de diversas instituições governamentais, como também de entes da iniciativa privada, a exemplo das instituições financeiras, cujo cenário de exacerbada criminalidade e consequente fluxo ilícito de ativos demonstra a necessidade de identificação de clientes e investidores que nelas depositam e investem recursos de origem espúria ou ignorada.

Diante da evolução tecnológica, os meios de comunicação entre as pessoas físicas e/ou jurídicas adquiriram velocidade antes inimaginável, independente do espaço geográfico no qual se encontram. Esse fator possibilitou o fácil acesso a serviços prestados por instituições financeiras, permitindo que organizações criminosas transnacionais movimentem recursos oriundos, normalmente, das mais diversas atividades ilícitas, como por exemplo, o tráfico de entorpecentes, o tráfico de armas, extorsão, corrupção, contrabando, exploração de jogos de azar e a exploração sexual.

Entretanto, para fazer uso dos recursos auferidos, as organizações criminosas necessitam realizar, além do planejamento operacional das referidas atividades (crimes antecedentes), o branqueamento de capitais, atividade comumente denominada de "lavagem de dinheiro". Esta etapa do planejamento organizacional visa revestir de caráter lícito o produto da atividade criminosa. 
Nos dizeres de Maia (2007, p. 13):

[...] a tendência contemporânea da reciclagem de dinheiro proveniente de crime (riciclaggio di denaro proveniente da reato), em algumas formaçôes sociais, aponta para a direção de uma autonomização desta atividade. Esta passa a ser cada vez mais um segmento terceirizado do mercado de serviços ilegais, proporcionada por especialistas, individuos e empresas, não só hábeis em elaborar complexas técnicas de escamoteação da origem ilícita de ativos mas habilitados a fornecer sofisticada assessoria na análise e gerenciamento de riscos e no estabelecimento de retaguarda jurídica para implementação de tais operações.

Observamos que verdadeiras estruturas organizacionais são montadas, contando com especialistas em investimentos, administradores de empresas, contadores, economistas, advogados e, inevitavelmente, agentes públicos cooptados para facilitar a consecução dos objetivos dessas organizações.

Nesse cenário, é imprescindível às instituições governamentais, mormente a polícia, buscar a profissionalização das atividades de investigação, na busca de novas tecnologias, objetivando a identificação dos membros das organizaçóes criminosas e dos caminhos percorridos pelos recursos provenientes das atividades ilícitas.

Diante desse cenário, várias ferramentas podem ser utilizadas sempre com o devido amparo legal, podemos citar o afastamento do sigilo das comunicações, fiscal e bancário, interceptações ambientais e a utilização de modernas ferramentas de análise. Neste diapasão, objetivamos nesta monografia apresentar as modernas ferramentas de análise de vínculos e a sua utilização no combate aos crimes de lavagem de dinheiro.

Apresentaremos a ferramenta de análise de vínculos Analyst's Notebook, adquirida pelo Departamento de Polícia Federal (DPF), desenvolvida pela empresa "i2 Limited" e comercializada no Brasil pela empresa “Tempo Real - Tecnologias de Informação”. Abordaremos as características que fazem com que tal ferramenta seja utilizada no combate ao crime de lavagem de dinheiro. 


\section{INTEligênCIA FinanCEIra e INVESTIGaÇÃo Criminal}

Segundo o Delegado de Polícia Federal Luiz Zampronha, inteligência financeira é a coleta e análise de informações financeiras e patrimoniais com o objetivo de identificar transações suspeitas, produzir provas criminais e/ou localizar bens, vantagens, direitos e valores provenientes direta e indiretamente de crimes $^{2}$.

Observamos que estão presentes os requisitos básicos da fundamentação teórica do conceito de atividade de inteligência: busca e/ou coleta, análise e a tomada de decisão, traduzida no convencimento da autoridade policial para representar pelo indiciamento e/ou prisão dos acusados, mediante o escopo probatório formado.

Nos dizeres de Joanisval Gonçalves (2010, p. 32) a inteligência financeira possui quatro aspectos relevantes:

- Possibilidade de fazer cessar o lucro das atividades das organizações criminosas investigadas;

- Rastreabilidade das ações das organizações criminosas e de seus agentes;

- Possibilidade de ressarcimento ao erário dos recursos desviados pela organização criminosa investigada;

- Possibilidade de confisco para o Poder Público de quantias e bens oriundos de atividades ilícitas das organizações criminosas investigadas.

O Brasil é signatário da Convenção das Nações Unidas contra o Tráfico Ilícito de Entorpecentes e de Substâncias Psicotrópicas, promovida pela Organização das Nações Unidas, em 1988, na cidade de Viena.

Durante a Convenção de Viena foram abordados temas relativos ao combate à lavagem de dinheiro e assumidos compromissos por parte dos países participantes em aprimorar os instrumentos de fiscalização e controle, tipificando o crime de lavagem de dinheiro e criando agências governamentais de combate à lavagem de dinheiro, conhecidas como FIU (Financial Intelligence Unit) ou Unidades de Inteligência Financeira.

2 Anotações obtidas mediante palestra ministrada no I Curso de Análise Financeira e Investigação em Lavagem de Dinheiro, na Academia Nacional de Polícia, em Brasília, no ano de 2009. 
Como parte destes compromissos, o Brasil editou, em março de 1998, a Lei n. ${ }^{\circ} 9.613$, que além de tipificar o crime de lavagem de dinheiro, criou no Ministério da Fazenda, o Conselho de Controle de Atividades Financeiras (COAF), que passou a ser a Unidade de Inteligência Financeira do Brasil. O COAF tem por objetivo promover a prevenção e o controle do delito de lavagem de dinheiro.

\section{Crime de Lavagem de dinheiro}

\subsection{ORIGENS HISTÓRICAS}

Diversas são as origens apontadas como sendo os antecedentes históricos desta atividade. Para Marcelo Mendroni (SNSP/MJ1, 2011, p. 5), sua origem foi a pirataria, tendo em vista a necessidade dos corsários de realizar a aquisição de alguns produtos (armas, munições, roupas, alimentos) em entrepostos comerciais, realizando o pagamento dessas mercadorias com recursos provenientes de suas ações criminosas. O professor João Carlos Abraços (SNSP/MJ1, 2011, p. 5) atribui sua origem à prática da usura durante a Idade Média, com o objetivo de fugir da proibição da Igreja a esta atividade. A expressão lavagem de dinheiro, do inglês money laundering, foi utilizada pela primeira vez em 1982, durante uma ação judicial nos Estados Unidos da América, em um caso que julgava a perda de recursos oriundos do tráfico de entorpecentes.

Outra perspectiva histórica da origem do crime de lavagem e dinheiro é apontada por Maia (2007, p. 22):

Em uma perspectiva histórico-evolutiva, a receptação é o primeiro delito cuja objetividade jurídica se aproxima do que atualmente constitui o escopo precip uo da incriminação da "lavagem" de dinheiro, qual seja, impedir a utilização de produtos de crime.

Seja qual for a origem histórica, a terminologia foi bastante difundida com o estudo das organizações criminosas americanas a partir do início do Século XX. Organizações que ficaram conhecidas por constituírem empreendimentos comerciais como, por exemplo, lava-rápidos e lavanderias com o objetivo de ocultar ou dissimular a origem ilícita do produto de crimes, para dar uma aparência lícita aos recursos oriundos das práticas dos crimes de prostituição, exploração do tráfico de bebidas alcoólicas e outras atividades ilícitas. 
De forma análoga, outras expressões são encontradas na literatura e nos ordenamentos jurídicos de diversos países. Edilson Bonfim e Márcia Bonfim (2008, p. 28) apontam que:

[...] também não existe um consenso a respeito da terminologia desta conduta. Enquanto alguns paises empregam a locução "lavar" (lavagem de dinheiro no Brasil, money laundering nos Estados Unidos e Inglaterra, Geldwäsche na Alemanha, lavabo de dinero na Argentina e México) e Geldwäscherei (na Suiça e na Austria), outros preferem "branquear" (blanqueo de dinero na Espanha, blanchiment de l'argent na França, branqueamento de capitais em Portugal e blanchissage de l'argent em parte da Suiça). Na Itália o fenômeno é chamado de riciclaggio del denaro.

No Brasil, a expressão lavagem de dinheiro encontra-se majoritariamente aceita pela doutrina e amplamente difundida na linguagem popular.

Quando esta prática foi associada aos crimes envolvendo o tráfico de entorpecentes, tomando proporções transnacionais, diversos países começaram a desenvolver instrumentos de fiscalização e controle, culminando com uma ação coordenada por parte desses países na tentativa de coibir tal atividade.

Nos dizeres de Edilson Bonfim e Márcia Bonfim (2008, p. 17):

Diante da gravidade e do caráter transnacional da lavagem de dinheiro, somente uma legislação internacional sincronizada, somada a uma eficiente cooperação interestadual, poderiam ser eficazes nos âmbitos de prevenção e repressão dessa prática. Essa constatação ocasionou uma união internacional de esforços, resultando na celebração de Convenções e Tratados, bem como na elaboração de Diretivas, Resoluções e Recomendações, todas elas com o objetivo de informar e prestar auxilio a diferentes paises em alguns casos e, em outros, de obrigá-los a aprovar normas internas com potencial para fazer frente a este tipo de conduta.

Neste diapasão foi realizada, em 1988, a Convenção das Nações Unidas contra o tráfico ilícito de entorpecentes e substâncias psicotrópicas, conhecida como "Convenção de Viena", tornando-se um importante marco no combate ao crime de lavagem de dinheiro. Nesse evento foi exigido, pela primeira vez, que os Estados tipificassem o crime de lavagem de ativos provenientes do tráfico de entorpecentes e substâncias afins, e norteou a constituição de mecanismos de cooperação inter- 
nacional no combate a esta prática. O Brasil ratificou esse instrumento por meio do Decreto n. ${ }^{o} 154$, de 26 de junho de 1991.

\subsection{O CONCEITO DE LAVAgEM DE DINHEIRO}

Lavagem de dinheiro refere-se a um processo de camuflagem da origem ilícita dos recursos (bens, valores e direitos) auferidos por atividades criminosas, com o objetivo de dar uma aparência de licitude, introduzi-lo no sistema financeiro, proporcionando sua livre utilização.

Gomez Iniesta (1996 apud CALLEGARI, 2008, p. 65) define a expressão lavagem de dinheiro como sendo

[...] a operação através da qual o dinheiro de origem sempre ilícita (procedente de delitos que se revestem de especial gravidade) é investido, ocultado, substituido ou transformado e restituido aos circuitos econômico-financeiros legais, incorporando-se a qualquer tipo de negócio como se fosse obtido de forma lícita.

Edilson Bonfim e Márcia Bonfim (2008, p. 28) definem a expressão como:

O processo composto por fases realizadas sucessivamente, que tem por finalidade introduzir na economia ou no sistema financeiro, bens, direitos ou valores procedentes dos crimes previstos no rol do artigo 1. ${ }^{\circ}$, caput, da Lei $n$. 9.613/1998, ocultando essa origem delitiva.

Essa definição faz referência ao rol dos crimes antecedentes, previstos na Lei n. ${ }^{\circ}$ 9.613/98, de 03 de março de 1998. Contudo, a edição da Lei n. ${ }^{\circ} 12.683$, de 09 de julho de 2012 , eliminou essa necessidade:

Art. $1^{\circ}$ Esta Lei altera a Lei n. ${ }^{\circ} 9.613$, de 3 de março de 1998, para tornar mais eficiente a persecução penal dos crimes de lavagem de dinheiro.

Art. 20 A Lei n. 9.613, de 3 de março de 1998, passa a vigorar com as seguintes alteraçôes:

"Art. 1. ${ }^{\circ}$ Ocultar ou dissimular a natureza, origem, localização, disposição, movimentação ou propriedade de bens, direitos ou valores provenientes, direta ou indiretamente, de infração penal.

$I$ - (revogado);

II - (revogado);

III - (revogado);

IV - (revogado); 


$$
\begin{aligned}
& \text { V-(revogado); } \\
& \text { VI-(revogado); } \\
& \text { VII -(revogado); } \\
& \text { VIII-(revogado). } \\
& \text { Pena: reclusão, de } 3 \text { (três) a } 10 \text { (dez) anos, e multa. }
\end{aligned}
$$

Observa-se, desta forma, que a intenção do legislador foi de possibilitar que quaisquer bens, direitos ou valores provenientes de atividades ilícitas possam ser objeto de investigação do crime de lavagem de dinheiro.

\subsection{Fases do Crime de Lavagem de Dinheiro}

Como exposto anteriormente, a lavagem de dinheiro visa camuflar a origem ilícita dos recursos auferidos em atividades criminosas, sem comprometer os agentes envolvidos. O GAFI apresenta um modelo que explica, de forma sistemática, esta atividade, subdividindo-a em três fases independentes, mas que podem ocorrer simultaneamente:

- placement (colocação/introdução);

- layering (ocultação/circulação/transformação/estratificação/dissimulação); e

- integration ou recycling (integração/reinversão).

\section{PLACEMENT}

Nesta etapa, os recursos são introduzidos no sistema financeiro, procurando distanciá-los de sua origem ilícita. Segundo informações publicadas na Apostila do Curso Combate a Lavagem de Dinbeiro (2009, p. 14), pela Coordenação-Geral de Pesquisa e Investigação (COPEI), da Secretaria da Receita Federal do Brasil (RFB),

A Colocação é a fase mais arriscada e vulnerável de todo o processo para o lavador de dinheiro, porque os recursos não têm origem justificável e apresentam maior visibilidade em função de seu volume, especialmente em função dos crescentes controles que os agentes econômicos têm implantado para a prevenção da prática do ilícito. 
Conforme Maia (2007, p. 37) "nesta fase busca-se a escamoteação (ocultação) inicial da origem ilícita, com a separação física entre os criminosos e os produtos de seus crimes".

Essa etapa pode ocorrer por meio de diversas operações, objetivando a aplicação dos recursos no sistema financeiro, dentre elas: envio de moedas para fora do país, compra de bens (móveis ou imóveis), uso de doleiros, transferências eletrônicas para paraísos fiscais, importação de mercadorias superfaturadas, fracionamento de depósitos em contas-correntes de pessoas físicas e/ou jurídicas, alteração de receitas de negócios (cinemas, restaurantes etc.), troca de moedas em casas de jogos (cassinos).

\section{LAYERING}

Visa estratificar a enorme quantidade de recursos introduzidos no sistema financeiro na etapa anterior, buscando-se justificar uma nova origem para os recursos. Nos dizeres de Maia (2007, p. 38):

[...] pretende-se com a dissimulação estruturar uma nova origem do dinheiro sujo, aparentemente legitima. Esta etapa consubstancia a "lavagem" de dinheiro propriamente dita, qual seja, tem por meta dotar ativos etiologicamente ilícitos de um disfarce de legitimidade.

Nesta etapa, o principal objetivo é dissociar os recursos de sua origem, ocorrendo normalmente por meio de diversas transferências entre instituições financeiras e transações comerciais, objetivando dificultar a reconstrução da trilha do papel (paper trail). Dentre as operações mais comuns podemos citar: transferências entre contas bancárias, utilização de "laranjas", realização de empréstimos falsos, importação e/ou exportação de mercadorias superfaturadas ou subfaturadas, mesclagem de recursos de origem ilícita com recursos de origem lícita.

\section{INTEGRATION OU RECYCLING}

Edilson Bonfim e Márcia Bonfim (2008, p. 36) definem como sendo a [...] etapa final do processo de lavagem de dinheiro. Aqui, os bens, direitos ou valores de origem delituosa, já com aparência lícita, em razão do sucesso nas fases anteriores são introduzidos novamente nos sistemas econômico e financeiro, aparentando tratar-se de operaçôes normais. 
Desse modo, as organizações criminosas buscam investir em empreendimentos pertencentes ao próprio grupo. Os meios mais utilizados são: compra de artigos de luxo (quadros, joias), recebimento de prêmios de seguros e concursos, abertura de empresas que possibilitem a sonegação real de receitas (supermercados, hotéis, casas de show), venda de imóveis.

Nesta etapa, conforme Callegari (2008, p. 56), "a menos que se haja podido seguir seu rastro através das etapas anteriores, será muito difícil distinguir os capitais de origem ilegal dos de origem legal".

As etapas da lavagem de dinheiro são independentes e podem ocorrer de forma simultânea, e a realização das três etapas não garante o sucesso da ação, bem como a eliminação de uma delas não implica em vulnerabilidade.

\subsection{Características do Crime de Lavagem de Dinheiro}

A constante evolução tecnológica e dos meios de comunicação entre as pessoas físicas e/ou jurídicas, realizada com velocidade antes inimaginável, independente do espaço geográfico no qual se encontram, possibilitou o fácil acesso a serviços prestados por instituições financeiras, permitindo que organizações criminosas transnacionais movimentem recursos oriundos de atividades ilícitas em várias partes do globo.

As organizações criminosas passaram então a utilizar os serviços prestados por instituições financeiras e/ou agentes promotores de comércio exterior para levar a cabo suas atividades de lavagem de dinheiro, tornando este crime transnacional e aliando a suas estruturas profissionais experientes em diversas áreas do conhecimento, como advogados, contabilistas, economistas, especialistas em investimentos e comércio exterior, buscando uma completa profissionalização da atividade.

A Coordenação-Geral de Pesquisa e Investigação (COPEI), da Secretaria da Receita Federal do Brasil (RFB), consoante as informações contidas na apostila mencionada acima (2009, p. 14), aponta três características fundamentais do crime de lavagem de dinheiro:

- complexidade - a lavagem de dinheiro a cada dia adota esquemas e métodos mais sofisticados, com uso de novas tecnologias, dificultando a sua identificação; 
- profissionalização - seja pela separação entre as atividades delituosas e as de lavagem dentro das organizações criminosas, seja pela existência de profissionais especializados que oferecem seus serviços a várias organizações;

- caráter transnacional - em vista das dificuldades da cooperação judiciária internacional e pela canalização da lavagem a países ou jurisdições com sistemas menos rígidos de controle.

Callegari (2008, p. 37-43) apresenta uma classificação semelhante de características do crime de lavagem de dinheiro:

- Internacionalização das atividades de lavagem: observando que por diversas vezes a origem dos recursos encontra-se em local diverso do destinatário;

- Profissionalização do trabalho: referindo-se à contratação de profissionais capacitados para desempenhar as atividades necessárias e sofisticadas dentro da organização criminosa para efetivar as etapas da lavagem de dinheiro;

- Vocação de permanência: na maioria dos casos de delitos, "a atividade criminal se desenvolve dentro de coordenadas temporais claramente definidas que se concluem tão logo o autor alcance seu objetivo". O autor explica que o sucesso do crime de lavagem de dinheiro depende da estrutura organizacional e, consequentemente, da confiança nos membros da organização criminosa, criando um efeito de permanência;

- Complexidade ou variedade dos métodos empregados: as organizações criminosas reinventam os métodos de lavagem de dinheiro, em uma tentativa constante de burlar os meios de fiscalização e combate;

- Volume do fenômeno: a grande quantidade de recursos movimentados nesta prática delituosa é apontada como uma característica da atividade;

- Conexão entre redes criminosas: aponta para a necessidade de cooperação entre redes criminosas, a exemplo da conexão entre o tráfico de drogas e o tráfico de armas.

O conhecimento das etapas da lavagem de dinheiro e de suas características possibilita a compreensão do fenômeno e permite identificar e adotar formas de combate e investigação. Abordaremos a seguir, de forma sucinta, as principais técnicas de investigação do crime de lavagem de dinheiro. 


\subsection{Métodos de Investigação do Crime de Lavagem de DINHEIRO}

Karla Padilha Marques (2011, p. 35) aponta que uma das maiores dificuldades é investigar crimes que, normalmente estão associados ao de lavagem de dinheiro, a exemplo da corrupção, destacando que:

[...] quando sua prática vem associada ao delito de lavagem de dinheiro, cujos mecanismos de combate ainda não se encontram no nivel desejado, dada a especificidade e complexidade do tema, bem como, em face dos entraves processuais que são opostos, decorrentes, sobretudo, do instituto do sigilo bancário e da grande quantidade de recursos idôneos a procrastinar o feito por tempo excessivo, para os criminosos do colarinho branco.

Nas ações de investigação do crime de lavagem de dinheiro, pode-se partir da apuração dos crimes antecedentes, e.g., o tráfico de drogas, ou realizar a persecução no sentido inverso, iniciando do crime de lavagem para descortinar as atividades ilícitas anteriores.

Sérgio Moro (2010, p. 98) aponta que:

[...] é importante apurar as circunstâncias de vida do investigado, especialmente seu patrimônio, rendas declaradas e gastos de consumo. Gastos de consumo e patrimônio incompativeis com as rendas declaradas constituem indícios de crime de lavagem, especialmente se for possivel relacioná-los a algum delito antecedente. Por exemplo, a prova de que agente público possui patrimônio incompativel com suas rendas lícitas e de que utiliza subterfúgios para ocultá-lo, como a utilização de pessoas interpostas ou a declaração de rendimentos inexistentes, éuma prova consistente de crime de lavagem de dinheiro se o mesmo agente público estiver envolvido na prática de delito contra a Administração Pública.

Edilson Bonfim e Márcia Bonfim (2008, p. 73) apresentam a experiência da Fiscalia Especial para la Represión de los Delitos Económicos relacinados com la Corrupción, expondo que a investigação do crime de lavagem de dinheiro é feita de acordo com as fases desta atividade (colocação, ocultação e integração):

1) Apurações em torno das pessoas implicadas e as tramas societárias utilizadas (principais investigados e seus familiares, testas-de-ferro, pessoas de confiança, mandatários ou administradores de sociedades, sócios, acionistas, etc.); 
2) Investigações sobre os bens, capitais, instrumentos ou direitos suscetiveis de serem utilizados nas técnicas de lavagem, tais como: imóveis rústicos ou urbanos; bens e direitos afetos a atividades empresariais; valores mobiliários (ações, participações, divida pública, fundos de investimentos, obrigações, investimentos em futuro, etc.); depósitos em contas correntes ou de poupança; direitos reais: como o arrendamento; concessóes administrativas; cartóes de crédito; operaçôes exteriores; avais; empréstimos; créditos; etc.

O ordenamento pátrio traz previsão de meios especiais de investigação, com destaque para:

- Lei n. 9.296/96: interceptação das comunicações telefônicas e telemáticas;

- Lei n. 9.807/99: proteção de testemunhas e criminosos colaboradores;

- Lei Complementar n. ${ }^{\circ}$ 104/01: quebra de sigilo fiscal;

- Lei Complementar n. ${ }^{\circ}$ 105/01: quebra de sigilo financeiro;

- Lei n. ${ }^{\circ}$ 12.683/12: ação controlada na lavagem de dinheiro;

- Lei n. ${ }^{\circ}$ 12.694/12: define organizações criminosas e dispõe sobre o processo e o julgamento de crimes praticados.

Os dispositivos legais previstos na persecução penal do crime de lavagem de dinheiro resultam em fontes de informações - bumint (fontes humanas), sigint (inteligência de sinais) e osint (fontes abertas) - e na obtenção de diversos dados que necessitam de compilação e análise. Os dados brutos necessitam passar por uma etapa de processamento e posterior análise, com o intuito de identificar as pessoas físicas e/ou jurídicas envolvidas, as movimentações financeiras e/ou patrimoniais e o modus operandi adotado pela organização investigada. Esta análise pode ser facilitada por meio do uso de ferramentas automatizadas.

Dentre as diversas ferramentas disponíveis no mercado, destacaremos a utilização das ferramentas de análise de vínculos, com ênfase na suite de softwares desenvolvida pela empresa "i2 Limited" e comercializada no Brasil pela empresa “Tempo Real - Tecnologias de Informação”. Abordaremos as características que fazem com que tal ferramenta seja bastante utilizada no combate ao crime de lavagem de dinheiro. 


\subsection{Ferramentas de Análise de Vínculos e sua Utiliza- Ção na Investigação de Crimes de LaVagem de Dinheiro}

O combate aos crimes praticados por organizaçóes criminosas, em um mundo globalizado e em constante evolução tecnológica, impõe às instituições policiais grandes investimentos em aperfeiçoamento técnico e profissional de seus quadros e em infraestrutura tecnológica.

Neste diapasão afirmam Celso e Moresi (2008, p. 2) que:

As organizaçôes criminosas exercem suas atividades sem divisas ou fronteiras, demonstrando poder de articulação, planejamento e sofisticação. O narcotráfico, contrabando, pirataria, crimes financeiros, corrupção, fraudes milionárias são as áreas preferidas, bem como a imensidade de outros delitos que assumem uma condição quase imbativel, causando prejuizo incalculável ao Estado e à sociedade em geral.

Cada vez mais a atividade policial defronta com situações complexas, exigindo mais da investigação. Diante desta situação, as organizaçôes buscam e fazem uso da tecnologia da informação, edificam infra-estruturas com o objetivo de obter mais rapidamente informaçôes e busca de significado e conhecimento sobre o crime.

Dessa forma, os agentes de segurança pública necessitam obter novos conhecimentos e desenvolver modernas técnicas de investigação. Este processo de aprendizado, organizacional e individual, é realizado por meio da cognição, assim definida no dicionário eletrônico Aulete (2007, grifo nosso):

1. Capacidade ou processo de adquirir e assimilar percep̧ỗes, conhecimentos;

2. Conjunto dos processos da mente envolvidos na percepção, na representação, no pensamento, nas associaçôes.

Observa-se que cognição diz respeito à maneira como adquirimos, armazenamos e utilizamos os conhecimentos apreendidos. Desde a infância crianças passam a perceber o ambiente, identificando pessoas, animais e objetos, o que de forma genérica, denominaremos de entidades, ou seja, tudo o que existe ou que se supõe existir. Toda entidade possui uma representação visual que a identifica, que caracteriza uma espécie dentro de um gênero (e.g. cavalo é uma espécie do gênero animal). 


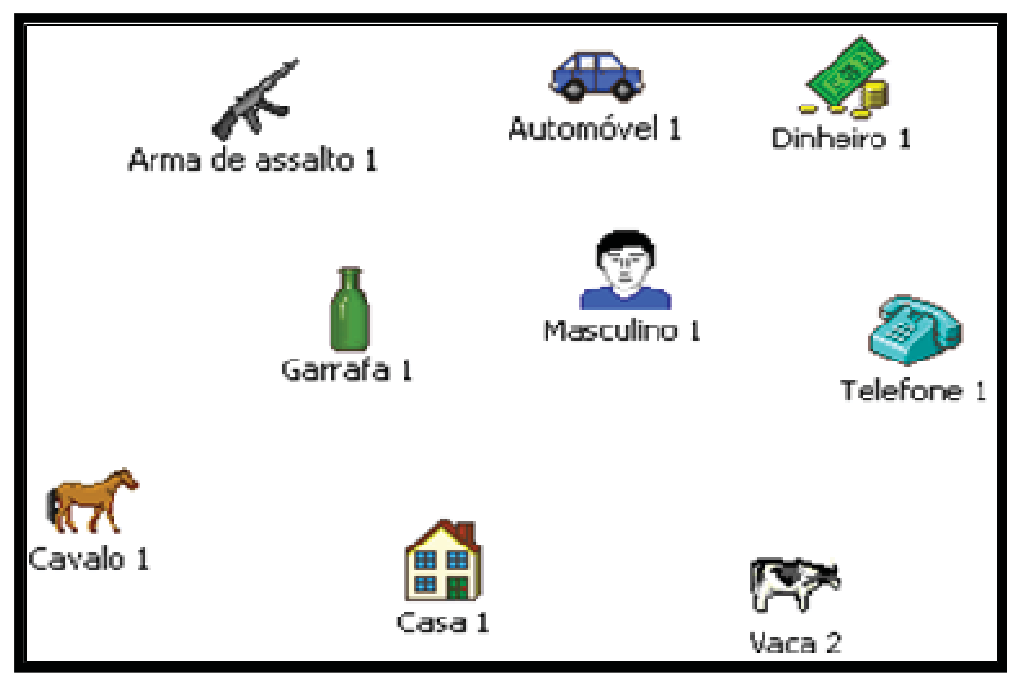

Figura 1 - Ícones de entidades do software Analyst's Notebook v.8.

Outro aspecto importante da cognição é a faculdade de verificarmos como as diversas entidades de um ambiente estão associadas, ou seja, relacionadas. A esta associação denominaremos vínculo. As associações (vínculos) entre entidades também possuem representações visuais:

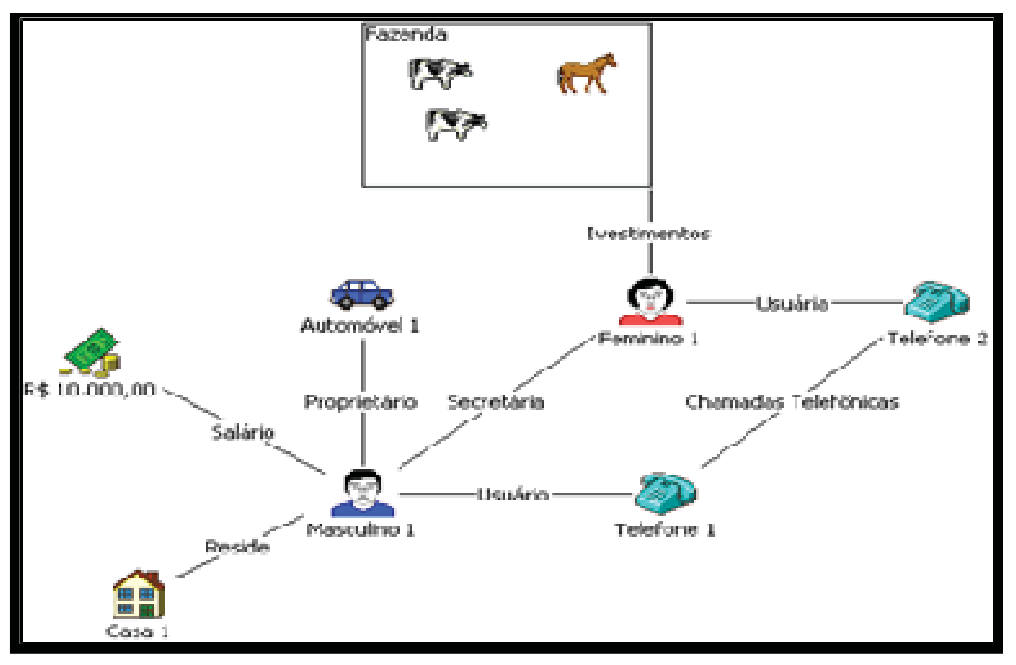

Figura 2 - Diagrama de vínculos do software Analyst's Notebook v. 8.

O sucesso do esforço de agentes de segurança e/ou de fiscalização, dentre outros fatores, decorre da capacidade de perceberem o ambiente da investigação, quais as entidades presentes (pessoas, organizações, contas-correntes, veículos etc.) e quais os vínculos que possuem (propriedade, comunicação, subordinação, afeto, financeiro etc.).

As instituições de segurança ou fiscalização dispõem de grande quantidade de informações, decorrentes de diversas fontes distintas. 
Essas informações por vezes não demonstram correlação aparente, mas podem embutir indícios de vinculação entre entidades e demonstrar padrões de comportamento.

Nos dizeres de Dantas e Ferro (2009, p. 26):

[...] a investigação policial e administrativa precisa ser hoje multifacetada, dado a complexidade de seus objetos, devendo poder realizar as seguintes açôes: (i) verificar a existência de elementos associáveis; (ii) identificar as relaçôes entre fatos $e$; (iii) construir modelos de informação sintetizada, possibilitando a compreensão da investigação como um todo e de suas partes constitutivas singularmente.

A metodologia que possibilita a consecução dessas ações (identificar entidades, vínculos existentes entre eles e representar suas associações) de forma mais eficaz para a atividade investigativa é a Análise de Vínculos - AV (Link Analysis).

\section{Ferramentas de Análise de Vínculos}

Segundo Ferro (2008, p. 244):

Análise de Vinculos éuma ferramenta utilizada para a compreensão de grandes volumes de dados, pois permite a visualização pormenorizada de cada parte de um todo e grupos de informações complexas.

A origem desta técnica está na construção de sociogramas, que tinham por objetivo medir e mapear relação entre indivíduos ou grupos sociais.

As investigações policiais tradicionais mantinham como escopo a verificação da existência de associações entre indivíduos para a prática delituosa, mas esse trabalho dependia da experiência e vivência dos investigadores.

A adoção, por parte das instituições de segurança pública, de técnicas oriundas da atividade de inteligência clássica (Inteligência de Estado) fez surgir nas investigações, modelos de descrição de associações, a exemplo da matriz de análise de vínculos (Figura 3). 


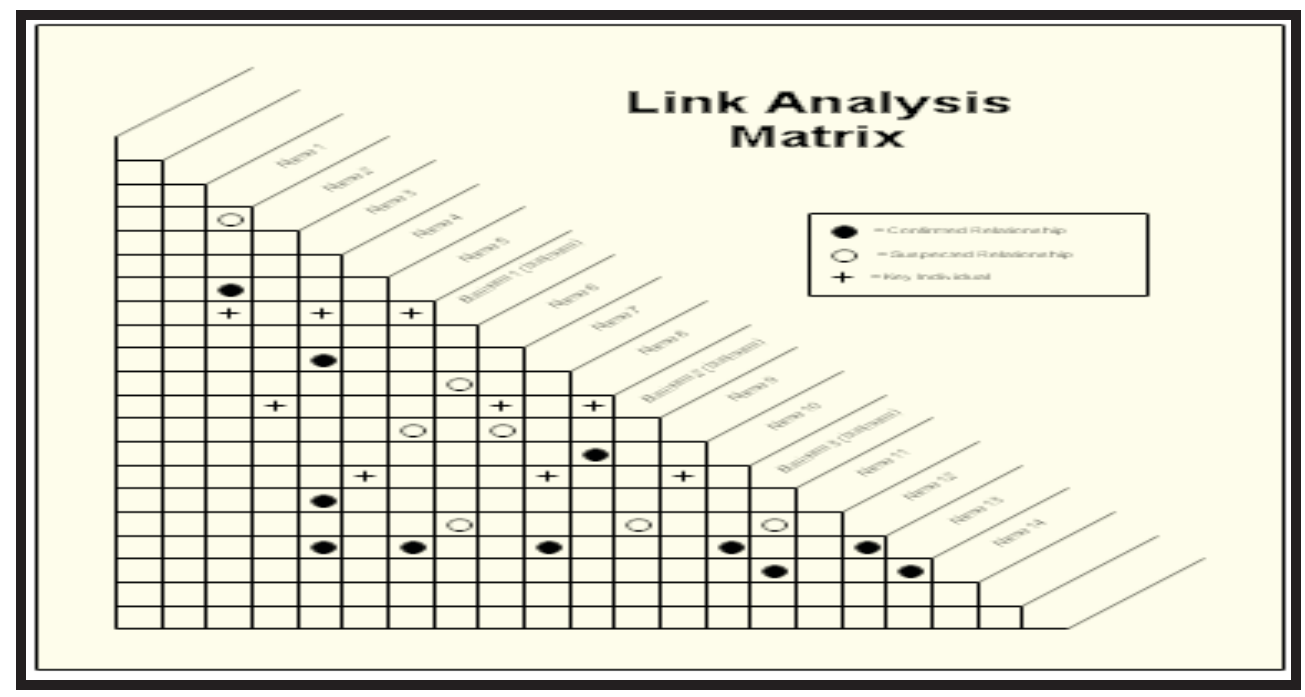

Figura 3 - Matriz de análise de vínculos.

A acelerada evolução da Tecnologia da Informação (TI) fez surgir vários softwares que possibilitam o armazenamento de grande quantidade de informações em bancos de dados e a posterior análise automatizada de seus relacionamentos (modelo conceitual denominado de entidade-relacionamento, concebido, em 1976, por Peter Chen).

No Departamento de Polícia Federal (DPF) o primeiro trabalho realizado com ferramentas de AV ocorreu no ano de 1990, quando da investigação do assalto ao Banco Central do Brasil, na cidade de Salvador/ BA. Durante os trabalhos de investigação, foram assassinados os Agentes de Polícia Federal Afonso Pedreira e Gilvan Santos. O homicídio foi praticado por uma organização criminosa, da qual faziam parte o advogado Franklin Matos e alguns policiais civis e militares baianos.

Para auxiliar nas investigações, o Agente de Polícia Federal José Adones de Oliveira Bezerra, lotado à época no Centro de Dados Operacionais (CDO), desenvolveu o Sistema de Análise Matricial de Chamadas Telefônicas - SISMAT, com o objetivo de documentar e analisar as chamadas telefônicas efetuadas pelas pessoas investigadas. Posteriormente, o SISMAT passou a compor um módulo do software Project $X$ (Projeto $\mathrm{X}$ ), uma plataforma de banco de dados que estava sendo desenvolvida em parceria com agentes policiais de outros países e trabalhava em conjunto com o software Analyst's Notebook, da empresa britânica "I2". 
$\mathrm{Na}$ atualidade, diversas empresas de TI desenvolvem soluções para a área de inteligência e análise criminal. No Brasil, são comercializados, entre outras soluções, os sistemas NEXUS, da "Dígitro" e o WEBTIGER, da "Wytron". O DPF utiliza em suas atividades de investigação a suíte de softwares "I2" (banco de dados Ibase, Analyst's Notebook, TextChart, Ixa, PatternTracer), de propriedade da multinacional "IBM I2" e distribuída com exclusividade no Brasil pela empresa "Tempo Real - Tecnologias da Informação".

\section{Característica das Ferramentas de Análise de VínCulos (AV)}

Dantas e Ferro (2009, p. 30) definem que a análise de vínculo:

[...] possibilita ao investigador a visualização de diferentes elementos funcionais e estruturais da investigação correspondente. De maneira sintética, a técnica engloba a captura, armazenamento e diagramação de informações pertinentes aos chamados "alvos monitorados", emprestando um valor agregado ao trabalho investigativo e que está fora do alcance prático da cognição humana normal.

Para possibilitar a realização do trabalho investigativo, citamos algumas características desejáveis nas ferramentas de AV.

\subsection{INTERfaCe AMigável}

O trabalho desenvolvido por analistas criminais ou de fiscalização requer muita atenção e concentração. Uma característica desejável para as ferramentas de AV é que possuam uma interface prática e intuitiva, possibilitando a inclusão/modificação de dados e realização de pesquisas sem a necessidade do analista possuir conhecimentos de linguagens de programação.

\subsection{Criação de Banco de Dados}

A ferramenta deve permitir a inclusão, armazenamento, fácil recuperação das informações, promover a fácil interação com outras fon- 
tes de dados, a exemplo de um processo que permite a importação de informações de outra base de dados, e a consequente criação automática das entidades e dos vínculos existentes na base de dados Ibase.

\subsection{Facilidade de Pesquisa (Entidades e Vínculos)}

A facilidade de montagem de pesquisas (queries) para a localização de entidades isoladas ou de várias entidades que atendam a determinados parâmetros informados, bem como de suas imediatas vinculações, é uma característica essencial nas ferramentas de análise de vínculos. Essa característica facilita o trabalho do analista quando da necessidade de recuperação das informações constantes no banco de dados, trazendo agilidade na realização da tarefa.

\subsection{Facilidade de Representação dos Vínculos Existen- TES ENTRE AS ENTIDAdES (DiAgRAMAÇÃo)}

As ferramentas de AV utilizam recursos de diagramação que facilitam o entendimento de complexas estruturas organizacionais e dos vínculos que ocorrem entre elas. Dantas e Ferro (2009, p. 11) afirmam que a "visualização da informação, ou 'inteligência visual', é parte essencial da inteligência humana, em sua capacidade específica de percepção ou cognição a partir de símbolos, códigos e sinais [...].”.

A possibilidade de fácil visualização de estruturas de relacionamentos torna possível a interpretação e a posterior tomada de decisões por parte da equipe de investigação e/ou fiscalização.

A Figura 4 demonstra uma associação entre pessoas investigadas e constatação de que um dos "alvos" aparece com entidades distintas. Essa afirmativa só foi possível devido ao cruzamento de informações de chamadas telefônicas e de dados cadastrais. Essas informações poderiam ser expressas em relatórios, porém seriam de mais difícil compreensão do que a demonstração visual da AV. 


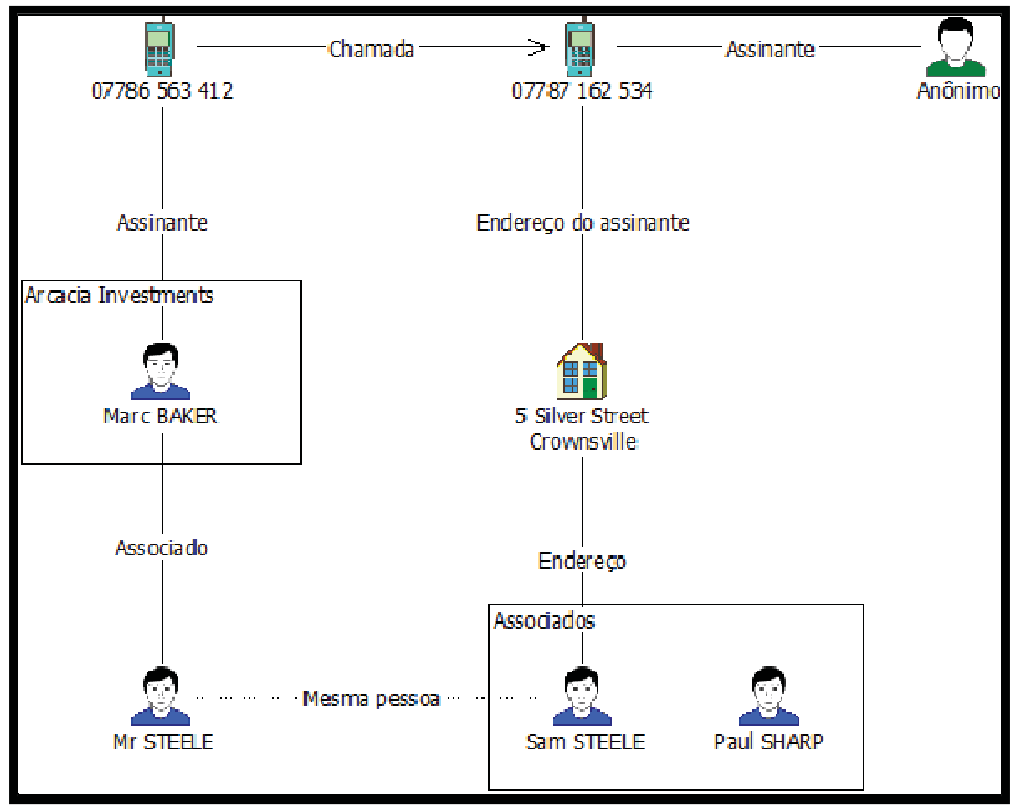

Figura 4 - Diagrama de vínculos (Material didático Analyst's Notebook).

\subsection{REPRESENTAÇÃO TEMPORAL}

As ferramentas de AV permitem a diagramação e a apresentação dos eventos (entidades e seus relacionamentos) no espaço temporal, facilitando a compreensão. A Figura 5 apresenta a representação de chamadas telefônicas (vínculos) ocorridos entre diversos telefones (entidades) em um determinado espaço temporal.

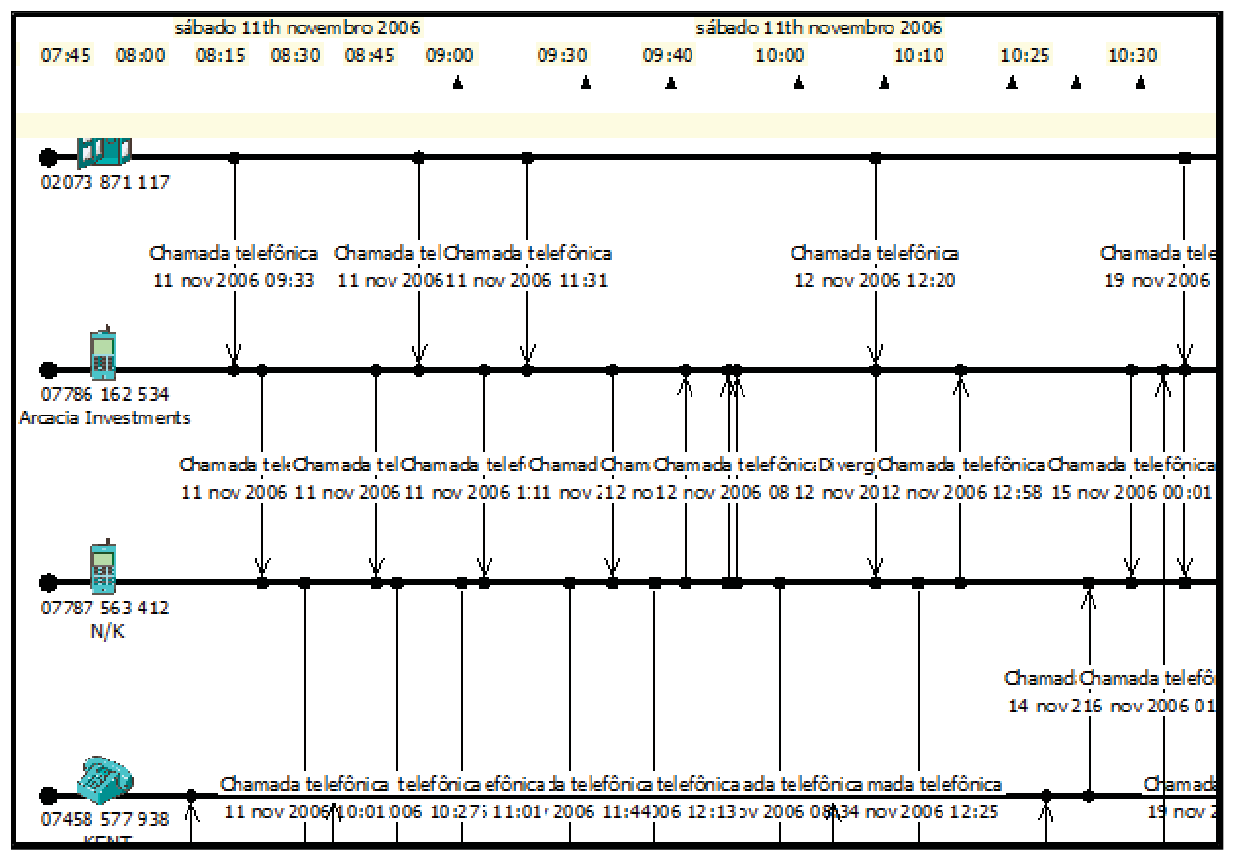

Figura 5 - Chamadas telefônicas em linha de tempo - (Material didático Analyst's Notebook) 


\subsection{ANÁlise de Redes Sociais}

Redes sociais são constituídas por entidades conectadas por vínculos (links).

O desenvolvimento da capacidade cognitiva do investigador, quando analisando as redes sociais de uma organização criminosa, permitirá que ele consiga perceber com facilidade o ambiente da investigação, identificando as entidades e os vínculos existentes entre elas, conforme afirmam Xu e Chen (2005, p. 203):

In addition to studying roles of individual members, crime investigators also need to pay special attention to subgroups in criminal enterprises. Each subgroup or team may be responsible for specific tasks. Group members have to interact and cooperate to accomplish the tasks. Therefore, detecting subgroups in which members are closely related to one another can increase understanding of a network's organization ${ }^{3}$.

As análises dessas estruturas e de seus relacionamentos permitem aos investigadores determinar importantes informações:

a) Quantidade de ocorrências de uma determinada entidade ou vínculo - frequência (Figura 6). Esta análise permite identificar a vinculação entre entidades e determinar os padrões de relacionamento, bem como suas mudanças no transcorrer da investigação;

b) Quais as entidades se relacionam e encadeiam-se - rede de contatos - possibilitando a descoberta de entidades até então ocultas (Figura 7);

c) Identificação de nódulos centrais na rede de relacionamentos pontos de convergência (Figura 8). Esta análise permite identificar entidades centralizadoras de contatos ou aparentemente determinantes de ações dentro da organização investigada.

3 Além de investigar individualmente os papéis dos membros, investigadores criminais também precisam dar atenção especial aos subgrupos da organização criminosa. Cada subgrupo pode ser responsável por tarefas específicas. Os membros do grupo têm de cooperar e interagir para poder realizar suas tarefas. Então, ao descobrir subgrupos, onde os membros estão intimamente relacionados, pode-se compreender melhor a organização da rede (Tradução nossa). 


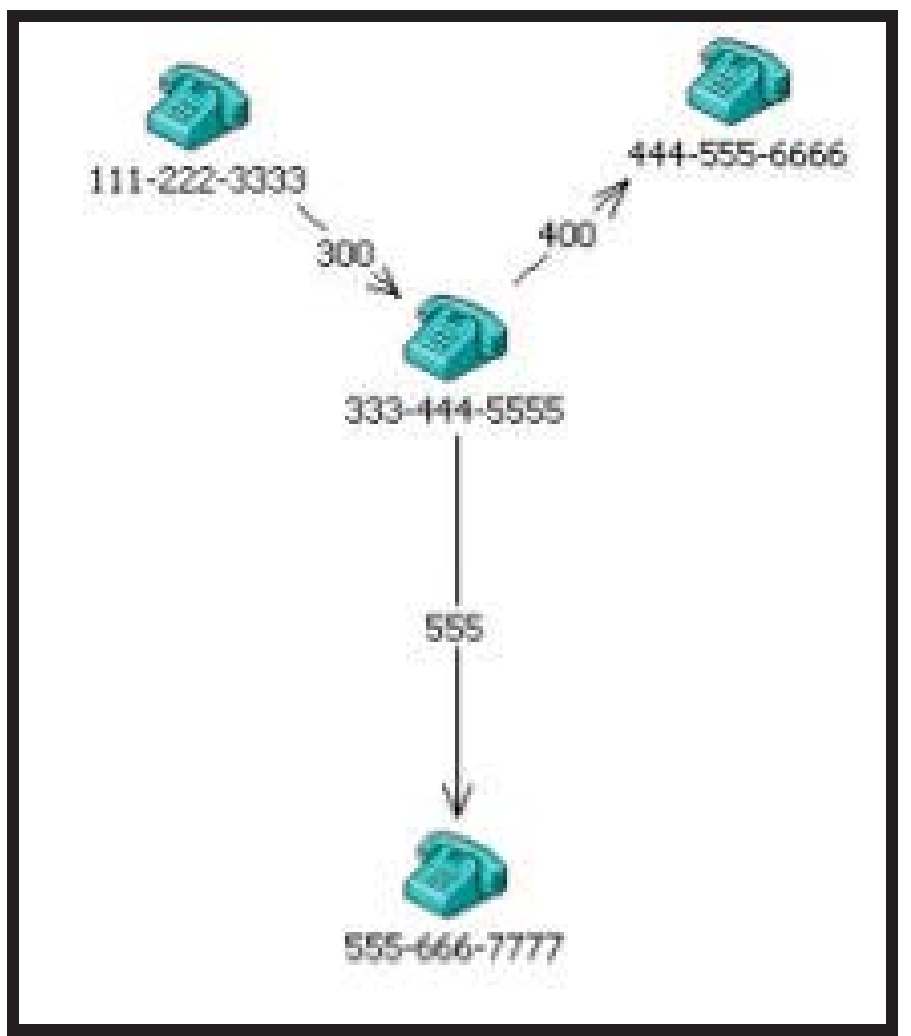

Figura 6 - Frequência de chamadas telefônicas (Material didático Analyst’s Notebook).

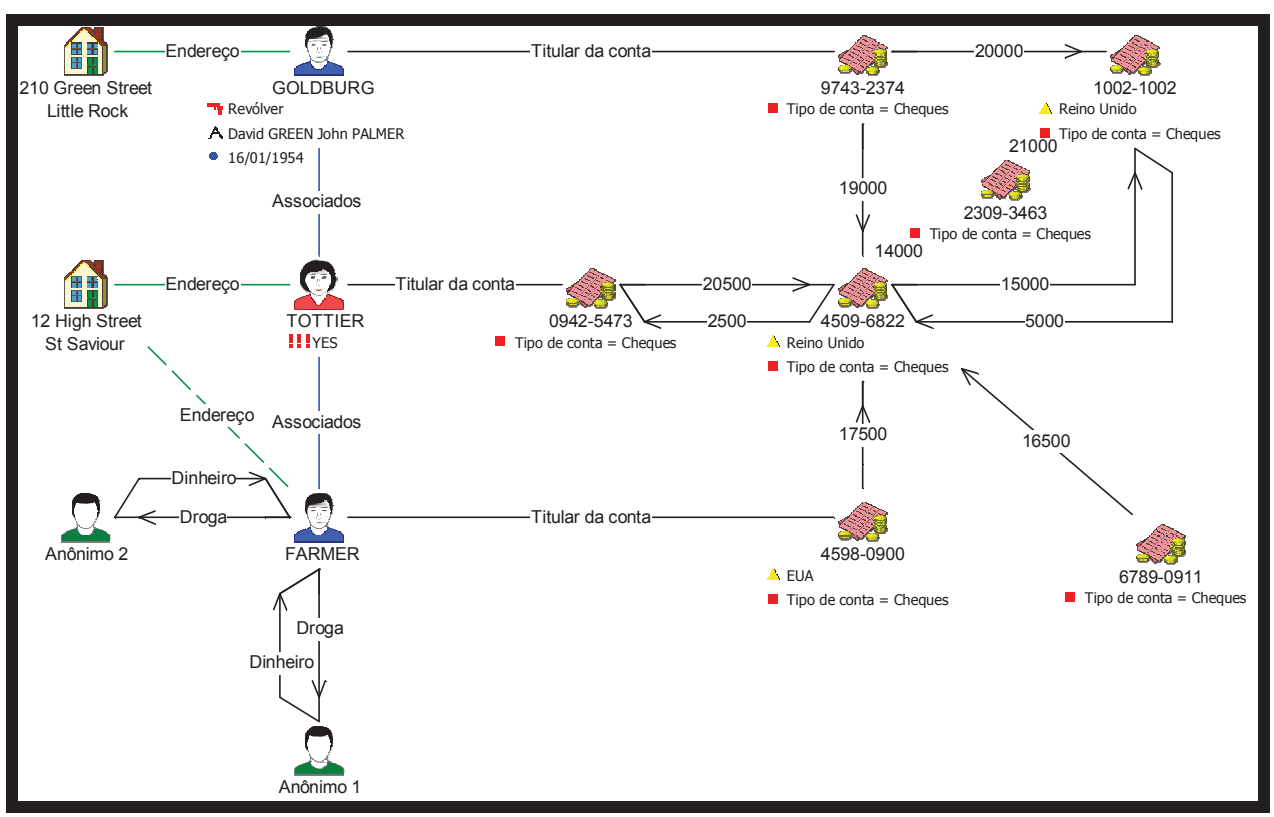

Figura 7 - Rede de contatos (Material didático Analyst's Notebook). 


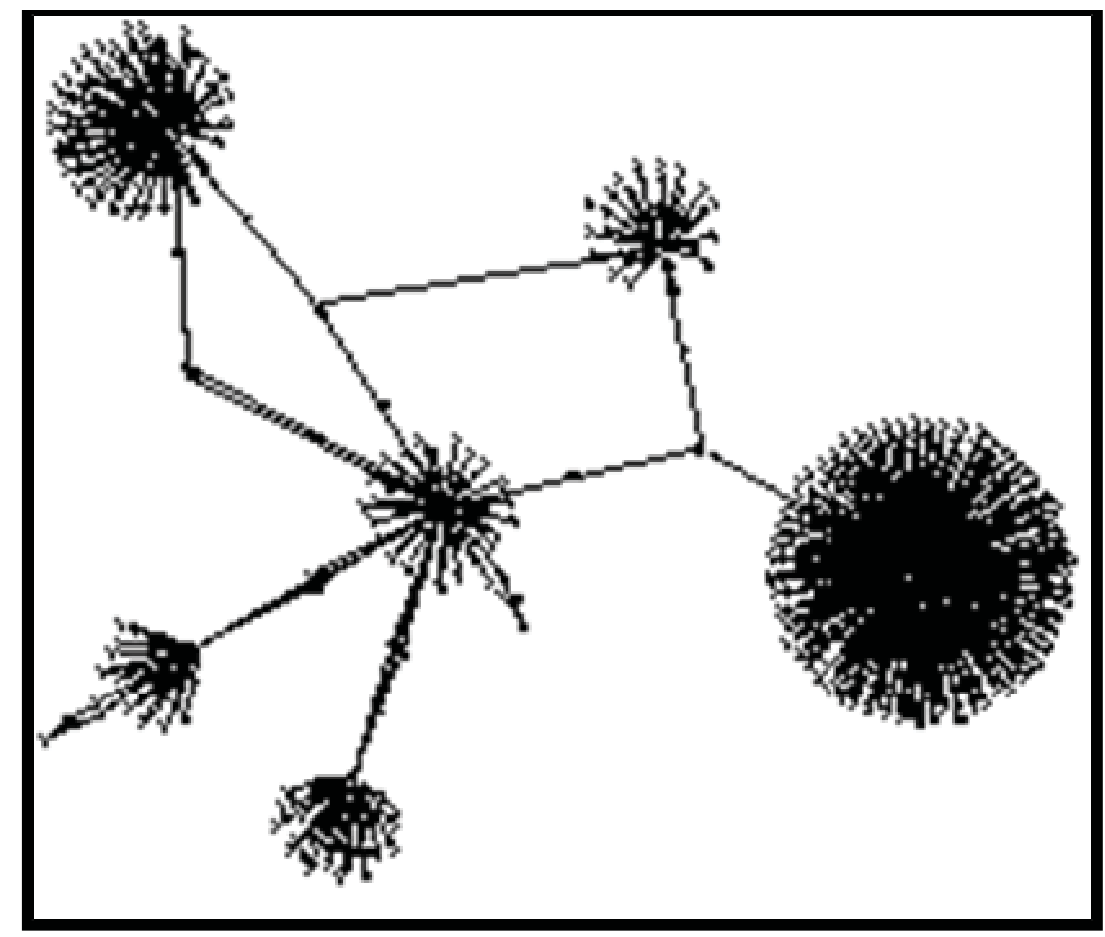

Figura 8 - Pontos de convergência (Material didático Analyst’s Notebook).

A versão 8.0 do Analyst's Notebook traz embutida uma funcionalidade extra de análise de redes sociais - a medida de centralidade - que permite, por meio de algoritmos, especialmente concebidos, identificar as entidades mais importantes de um diagrama, ou seja, as que ocupam posição estratégica dentro da organização. Para exemplificarmos essas funcionalidades, tomaremos por base o diagrama constante na Figura 9.

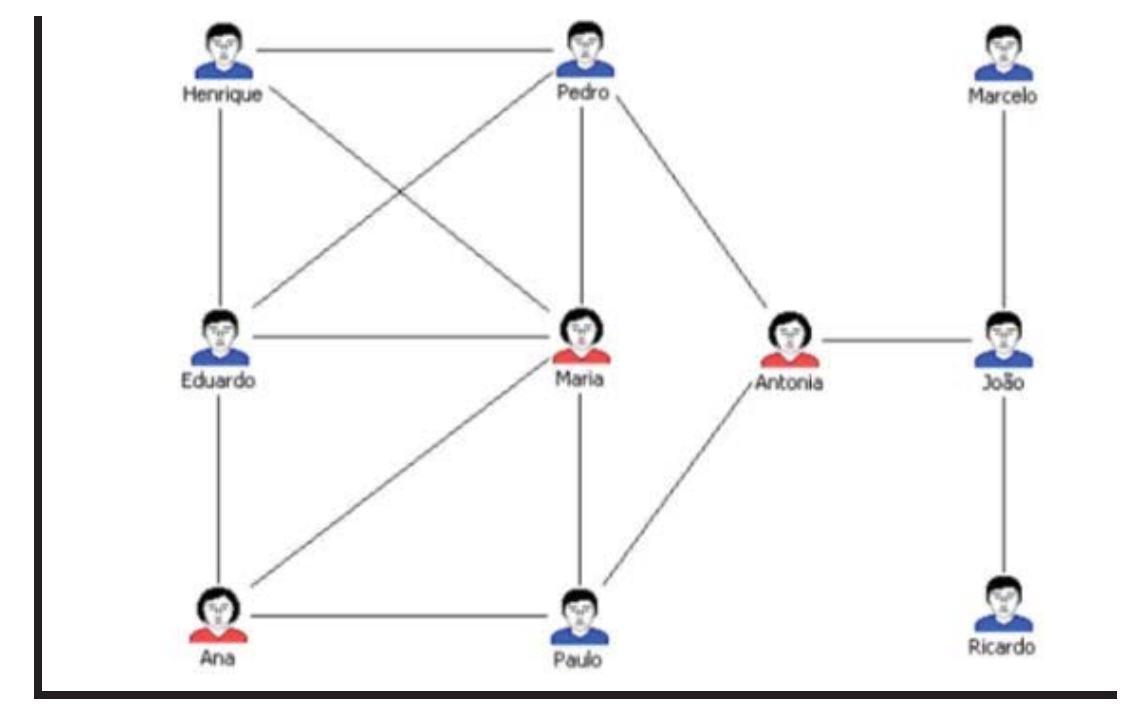

Figura 9 - Relacionamento entre pessoas (Material didático Analyst's Notebook). 
Essa funcionalidade permite três diferentes formas de análise: intermediação, proximidade e grau.

Intermediação - visa identificar entidades que conectam subgrupos que de outra forma estariam desconectados. No exemplo da Figura 9, esta entidade seria Antonia.

Proximidade - refere-se à rapidez na interação entre entidades, ou seja, procura identificar o menor número de vínculos que existe para que uma entidade chegue até outra. No diagrama acima, essa entidade é Antonia, tendo em vista que ela é capaz de disseminar uma informação entre toda a rede de forma mais rápida.

Grau - é uma medida de centralidade que visa identificar a entidade mais ativa dentro da organização, ou seja, aquela que possui o maior número de conexôes. No exemplo da Figura 9, essa entidade é Maria.

\subsection{Emprego das Ferramentas de Análise de Vínculos Na InvestigaÇão de Crimes de LAVAgem de Dinheiro}

As instituições brasileiras envolvidas no esforço ao combate à corrupção e à lavagem de dinheiro no Brasil criaram, no ano de 2003, a Estratégia Nacional de Combate à Corrupção e à Lavagem de Dinheiro ENCCLA, consistindo na articulação de diversos órgãos integrantes dos três poderes da República (Executivo, Legislativo e Judiciário), Ministérios Públicos e sociedade civil.

A ENCCLA foi responsável por diversas ações que objetivaram o combate à lavagem de dinheiro e à corrupção, dentre elas podemos citar:

- Criação do Programa Nacional de Capacitação e Treinamento para o Combate à Corrupção e à Lavagem de Dinheiro (PNLD);

- Criação do Cadastro de Clientes do Sistema Financeiro Nacional (CCS);

- Implementação do Sistema Nacional de Bens Apreendidos (SNBA), no âmbito do Conselho Nacional de Justiça;

- Estabelecimento de layout padrão para solicitação e obtenção de informações decorrentes de quebras de sigilo bancário. 
A padronização do layout das informações fornecidas pelas instituições financeiras foi determinada pela edição, pelo Banco Central do Brasil, da Carta Circular no 3.454/10, que trouxe também a previsão da utilização de sistemas de informática para transmissão e recepção dos dados informados no atendimento das solicitações.

O Departamento de Polícia Federal, órgão participante da ENCCLA, no ano de 2010, firmou um Acordo de Cooperação Técnica com a Procuradoria Geral da República, objetivando a transferência de tecnologia para criação de um sistema informatizado que possibilite a validação, transmissão, recepção e controle do atendimento das solicitações de quebra de sigilo bancário, o Sistema de Investigação de Movimentação Bancária (SIMBA).

A administração do SIMBA está a cargo do Serviço de Perícias Contábeis e Econômicas do Instituto Nacional de Criminalística - SEPCONT/ INC/DPF e acompanhados pela Divisão de Repressão a Crimes Financeiros - DFIN/DICOR/DPF.

Com a implantação deste sistema, a representação pelo afastamento do sigilo bancário feita pela autoridade policial, a autorização judicial, a comunicação pelo Banco Central do Brasil às instituições financeiras envolvidas e o atendimento da solicitação é feita de forma integrada e digital.

As informações fornecidas pelas instituições financeiras quando do cumprimento da decisão judicial são encaminhadas via SIMBA, de forma automática, para o Instituto Nacional de Criminalística do Departamento de Polícia Federal (INC/DPF), permitindo a análise por parte dos Peritos Criminais Federais.

Nas informações fornecidas pelas instituições financeiras, via SIMBA, devem constar ${ }^{4}$ :

- Dados das agências bancárias da instituição financeira;

- Identificação das contas que tiveram o sigilo bancário afastado e as contas da mesma instituição que realizaram quaisquer transações financeiras com as contas investigadas;

- Identificação das pessoas físicas e/ou jurídicas titulares das contas investigadas e das contas da mesma instituição que realizaram transações financeiras;

4 Instrução Normativa no 42/2010-DG/DPF, de 23 de novembro de 2010. 
- Lançamentos relacionados às contas investigadas;

- Identificação da origem e destino dos recursos referentes aos lançamentos efetuados nas contas investigadas.

As ferramentas de AV possuem módulos que permitem a importação de informações provenientes de outros sistemas informatizados, em diversos formatos, sendo os mais comuns os de texto (com ou sem formatação) e de planilhas de dados (e.g. Microsoft Excel). A ferramenta de AV utilizada pelo DPF, suíte de softwares "I2", possui a facilidade de importação dos dados constantes no SIMBA, uma vez que estão em formato padronizado para todas as instituições financeiras.

O banco de dados Ibase fornece junto com as licenças de utilização de usuário, licenças de designer 5 , que permitem a equipe de desenvolvimento promover as alterações necessárias no template (molde, modelo da base de dados) da aplicação. Ou seja, a própria equipe pode solicitar a criação de entidades que não existam na base de dados, inclusão ou alteração de campos dentro dessas entidades e novas possibilidades de vinculação entre entidades. Essa comodidade permite adequar a base de dados totalmente ao layout utilizado no SIMBA e padronizado pelo Banco Central do Brasil.

Os dados importados para o banco de dados Ibase irão interagir com as informações existentes, sendo possível, no momento da importação, a criação automática de entidade (pessoas, organizações, contas-correntes etc.) e dos vínculos existentes, fornecendo à equipe de investigação maior capacidade de análise da organização criminosa investigada.

Uma vez constante na base de dados Ibase, as diversas informações adquiridas (coleta e/ou busca) durante a investigação podem ser representadas de forma visual (diagramadas) e analisadas por meio de técnicas de análise de redes sociais, com a utilização de softwares específicos, a exemplo do Analyst's Notebook, que integra a suíte de softwares "I2".

A Figura 10 apresenta a tela de inclusão da entidade "contas", inserida no banco de dados Ibase.

5 Profissional responsável pela elaboração do desenho da base de dados e de sua interação com o usuário final. 


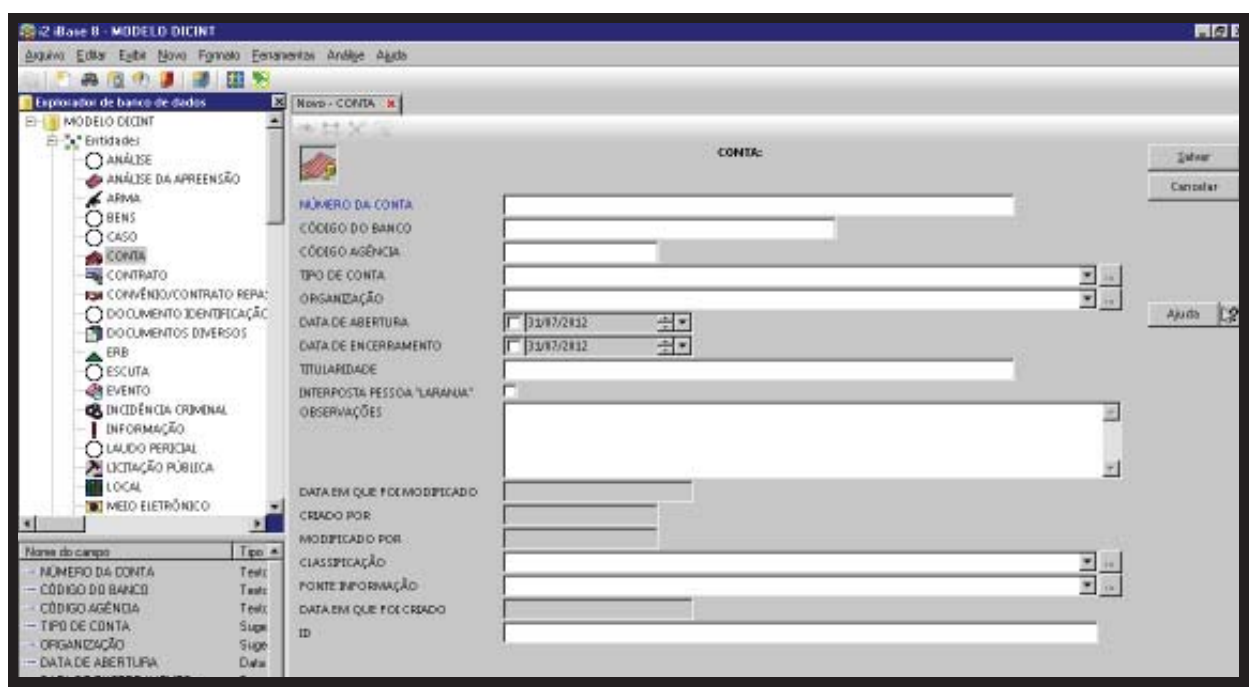

Figura 10 - Tela de inclusão da entidade conta no Ibase.

O template do Ibase permite a criação de vínculos entre as entidades, obedecendo ao que for determinado pelo designer. Abaixo, os tipos de entidades que podem ser ligadas pelo vínculo "transações financeiras":

\begin{tabular}{|c|c|c|}
\hline EXTREMIDADE 1 & EXTREMIDADE 2 & OBSERVAÇÕES \\
\hline Conta & Conta & $\begin{array}{c}\text { Movimentação entre } \\
\text { contas-correntes }\end{array}$ \\
\hline Organização & 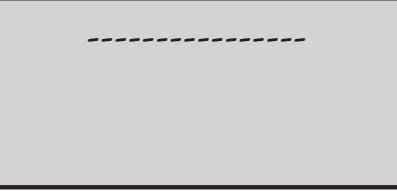 & $\begin{array}{c}\text { Movimentação entre } \\
\text { pessoa jurídica e contas- } \\
\text {-correntes }\end{array}$ \\
\hline Pessoa & --.---.---.--.-. & $\begin{array}{l}\text { Movimentação entre } \\
\text { pessoa física e contas- } \\
\text {-correntes }\end{array}$ \\
\hline
\end{tabular}

O software Analyst's Notebook permite a análise e a representação temporal de diversas transações financeiras (vínculos) ocorridas entre duas ou mais entidades "contas-correntes", expandindo ${ }^{6}$ as demais entidades relacionadas, a exemplo de pessoas físicas e/ou jurídicas titulares das contas, conforme exemplos abaixo:

6 Ato de demonstrar as entidades que possuem vinculação com a entidade analisada, por meio de pesquisas em camadas ou níveis. Essas informações necessitam constar no banco de dados. 


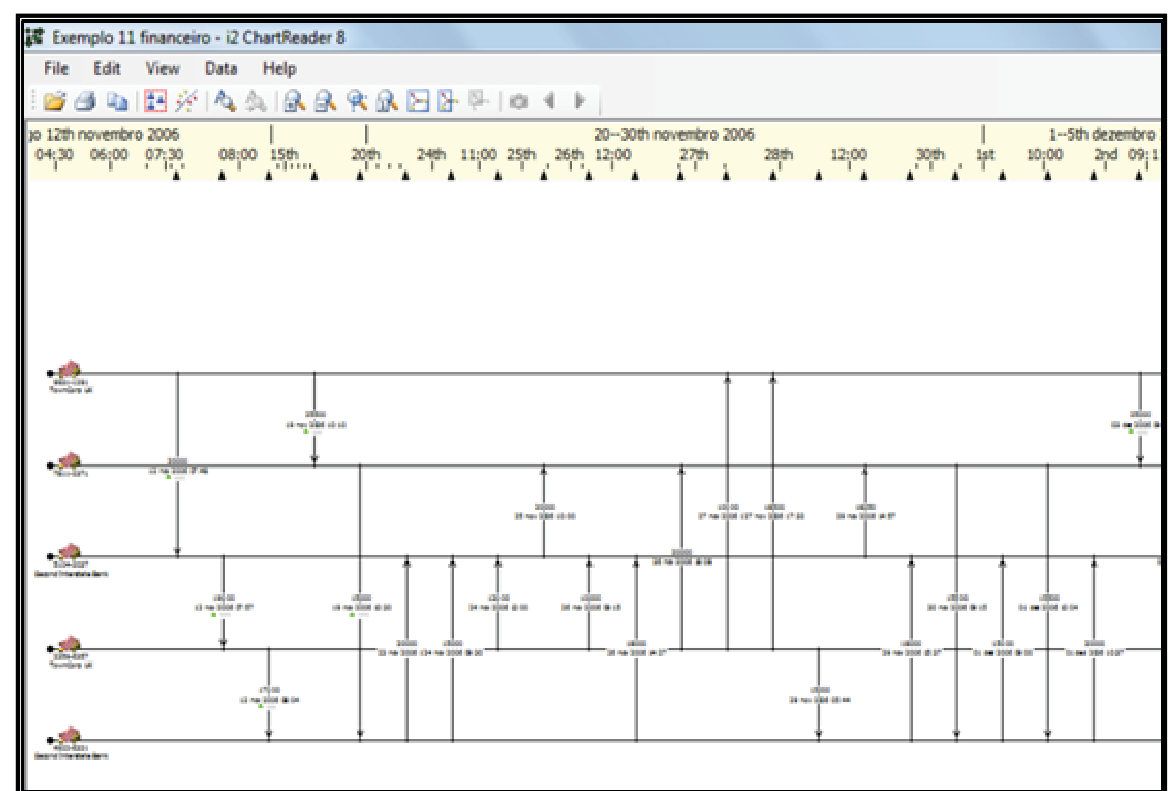

Figura 11 - Diagrama temporal de movimentações financeiras (Material didático Analyst's Notebook).

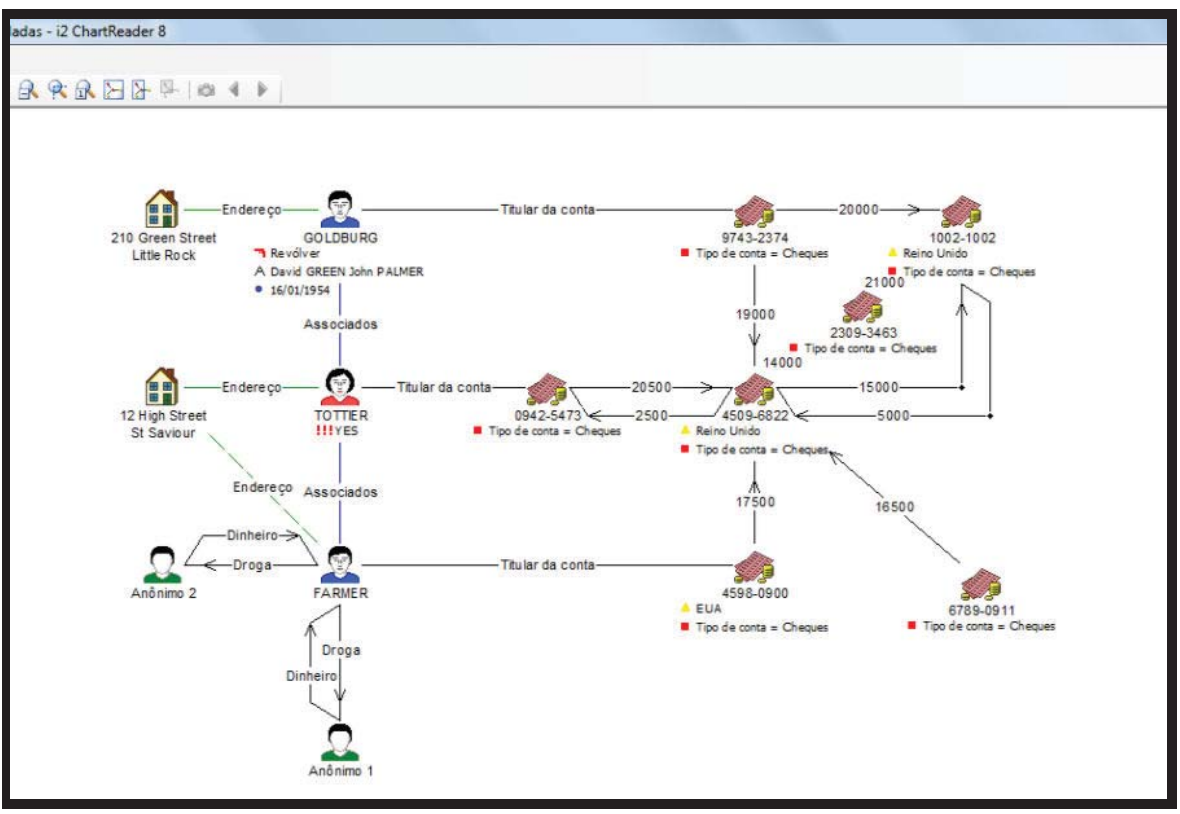

Figura 12 - Diagrama de expansão de uma das entidades conta (Material didático Analyst's Notebook).

As possibilidades de análise e descobertas provenientes da interação do SIMBA com as ferramentas de AV da suíte de softwares "I2" agregam valor às investigaçóes, tendo em vista a celeridade conferida e a confiabilidade dos dados analisados. 


\section{ConcLusão}

A globalização e a evolução dos meios de transmissão digital permitiram que as organizaçôes criminosas ultrapassassem as fronteiras físicas de seus países, tornando-se empreendimentos transnacionais. Na esteira desta transformação, essas organizações promoveram a remodelagem nas técnicas adotadas de lavagem de ativos provenientes de seus ilícitos.

Tais transformações desencadearam nos Estados uma reação imediata, em uma relação de causa e efeito, culminando com a formação de instituições internacionais de combate ao crime organizado e à lavagem de dinheiro, a exemplo do GAFI/FATF e do Grupo de Egmont.

As tradicionais técnicas de lavagem de dinheiro foram substituídas por complexas transações comerciais internacionais, a exemplo de superfaturamento/subfaturamento de exportaçóes e investimentos em empresas multinacionais, tudo com o objetivo de fugir das ações dos órgãos de fiscalização e repressão da criminalidade.

As mudanças de comportamento das organizações criminosas têm demandado esforços de diversas instituições governamentais e da iniciativa privada para identificar, neutralizar e combater os crimes por elas perpetrados, principalmente os de lavagem de dinheiro.

Os Estados incrementaram os investimentos na capacitação de profissionais (de inteligência e de segurança pública) e na aquisição de recursos tecnológicos (equipamentos e softwares) das suas instituições, possibilitando uma resposta eficaz no combate à corrupção e aos crimes de lavagem de dinheiro.

O aparato repressivo dos Estados passou a atuar de forma proativa, objetivando identificar em cada uma das fases do processo de lavagem de dinheiro (colocação, circulação e integração) os atores envolvidos, criando mecanismos de controle mais rígidos.

As instituições de segurança e fiscalização contam com metodologias próprias para realizar a análise das informações fornecidas pelas instituições financeiras, utilizando-se de softwares simples, a exemplo de planilhas de cálculos (e.g. Microsoft Excel) ou de sofisticados sistemas de processamento. 
No Brasil, podemos citar os esforços desprendidos pelas instituições que compõem a Estratégia Nacional de Combate à Corrupção e à Lavagem de Dinheiro - ENCCLA, a exemplo do Departamento de Polícia Federal - DPF e do Conselho de Controle de Atividades Financeiras (COAF), que nos termos da Lei n. ${ }^{\circ}$ 9.613/98 passou a ser a Unidade de Inteligência Financeira Nacional.

As informações coletadas por diversos sistemas de controle, a exemplo das comunicações feitas ao COAF pelas instituições - financeiras, bancárias, seguradoras, e outras - podem ser requisitadas, mediante autorização judicial, e analisadas com o objetivo de identificar os atores envolvidos em crimes de lavagem de dinheiro.

Outro importante marco da atuação da ENCCLA foi a padronização das informações fornecidas pelas instituições financeiras quando do atendimento aos pedidos feitos pelas instituições de segurança e fiscalização, amparados por determinação judicial. Esta padronização foi determinada pela Carta Circular n. ${ }^{\circ}$ 3.454/10 do Banco Central do Brasil, permitindo a utilização de sistemas de informática para realização desta atividade.

O Departamento de Polícia Federal, em parceria com a Procuradoria Geral da República, desenvolveu o Sistema de Investigação de Movimentação Bancária (SIMBA), com o objetivo de permitir a validação, transmissão, recepção e controle do atendimento das solicitações de quebra de sigilo bancário.

Os crimes de lavagem de dinheiro perpetrados por organizações criminosas, em regra, são de difícil investigação devido à mobilidade e da profissionalização dos membros encarregados desta tarefa. Contudo, as instituições de controle e de fiscalização podem lançar mão de diversos recursos e técnicas de investigação policial ou de inteligência, obtendo de diversas fontes, informações preciosas, que por vezes, parecem dispersas, mas que podem ter relação umas com as outras.

As informações obtidas em grande quantidade tornam a análise impraticável se forem utilizados apenas os recursos humanos disponíveis, por maior que seja a capacidade intelectual dos agentes envolvidos. Por outro lado, quando esses profissionais qualificados utilizam ferramentas específicas para o cruzamento e análise de grande quantidade de informações, denominadas ferramentas de análise de vínculos $(\mathrm{AV})$, os resultados obtidos são mais confiáveis e o tempo de investigação é reduzido. 
Essas ferramentas possuem peculiaridades e alto grau de tecnologia envolvido, desempenhando um papel importante como auxiliares na investigação de crimes de lavagem de dinheiro.

As ferramentas de $\mathrm{AV}$ possuem características que fazem com que sejam utilizadas para realizarem a descoberta e a análise de vínculos entre diversos atores (entidades), proporcionando às instituições, principalmente as de segurança e fiscalização, outras funções além da possibilidade de arquivamento das informações (banco de dados).

Tal assertiva faz com que elas sejam atualmente utilizadas por instituições policiais, Ministérios Públicos, Poder Judiciário, agências de inteligência estatal e até mesmo por entidades da iniciativa privada.

Cide Ferreira Romão Agente de Polícia Federal, lotado na SR/DPF/AL. Graduado em Ciências Contábeis. Especialista em Gestão Estratégica Empresarial. Especialista em Inteligência Policial pela Escola Superior de Polícia da Academia nacional de Polícia.

E-MAIL:CIDE.CFR@DPF.GOV.BR

\title{
The Use of Link Analysis Tools in Combating the Money Laundering Crimes
}

\begin{abstract}
This article approaches the techniques of investigation of crimes involving the money laundering, with emphasis on the use of link analysis tools. These tools play an essential role in the identification and consequent demonstration of the existing relationships between the various actors involved in money laundering crimes, allowing the preview and understanding of the structures of the criminal organizations investigated.
\end{abstract}

KEYWORDS: Link analysis. Money laundering. Criminal Investigation.

\section{REFERÊNCIAS}

ALVES, Charles F. Cognição na atividade policial: um estudo da tecnologia da informação aplicada à análise de vínculos na polícia civil do Distrito Federal. Academia de Polícia Civil do Distrito Federal: Faculdades Fortium. Brasília, 2009. 
ANTUNES, Priscila C. B. SNI \& ABIN: entre a teoria e a prática - Uma leitura da atuação dos Serviços Secretos brasileiros ao longo do século XX. Rio de Janeiro: FGV, 2002.

BONFIM, Edilson M.; BONFIM, Márcia M. M. Lavagem de Dinheiro. 2. ed. São Paulo: Malheiros, 2008.

BRASIL. Lavagem de Dinheiro: legislação brasileira. (Organizado por). Conselho de Controle de Atividades Financeiras, Federação Brasileira de Bancos. 2 ed. rev. Brasília: COAF. São Paulo: FEBRABAN, 2005.

. Decreto n..$^{\mathbf{4}}$.376, de 13 de setembro 2002. . Lei n. ${ }^{\circ}$ 9.883, de 07 de dezembro de 1999. . DEPARTAMENTO DE POLÍCIA FEDERAL. Manual de Inteligência Policial - Outubro de 2009. - Ministério da Justiça. Secretaria Nacional de Segurança Pública. Resolução n. ${ }^{\circ}$ 01, de 15 de julho de 2009. . Lei n. 9.613, de 3 de março de 1998. Diário Oficial [da] República Federativa do Brasil, Poder Executivo, Brasília, DF, 04 mar. 1998.

CALLEGARI, André L. Lavagem de Dinheiro: aspectos penais da Lei n. ${ }^{\circ}$ 9.613/98. 2. ed. rev. atual. Porto Alegre: Livraria do Advogado, 2008.

CEPIK, Marco A. C. Espionagem e Democracia: agilidade e transparência como dilemas na institucionalização de serviços de inteligência. Rio de Janeiro: FGV, 2003.

DANTAS, George. F. de L. Análise de Vínculos na Atividade Policial. Mimeo. 2004. ; FERRO JÚNIOR, Celso. M. A Descoberta e a Análise de Vínculos na complexidade da investigação moderna: algumas considerações sobre novas tecnologias \& inteligência visual. Rio de Janeiro: Tempo Real - Tecnologias de Informação, 2009.

FERRO JÚNIOR, Celso M.; MORESI, Eduardo A. D. "Inteligência Organizacional: identificação das bases doutrinárias para a investigação criminal”. In: Revista de Ciência da Informação, Rio de Janeiro, v. 9. n. ${ }^{\text {1 }}$, fev. 2008, DataGramaZero. 
GAFI/FATF. As Quarenta Recomendaçóes. Financial Action Task Force on Money Laundering. 20 jun. 2003.

GONÇALVES, Joanisval Brito. Atividade de Inteligência e legislação correlata. Série Inteligência, Segurança e Direito. Nirerói/RJ: Ed. Impetus, 2010.

KRIZAN, Lisa. Intelligence Essentials for Everyone. Washignton, DC/ EUA: NDIC PRESS, 1999.

I2 LIMITED. Analyst's Notebook 7: Guia rápido de introdução. 2007.

LEXIKON Editora Digital. “Cognição”. In: Dicionário Aulete Digital - Dicionário Contemporâneo da Língua Portuguesa. [S.l.]: LEXIKON Editora Digital, 2007, Windows [XP/ Vista/98/2000/2003/2007].

MAIA, Rodolfo T. Lavagem de Dinheiro: anotações às disposições criminais da Lei n. ${ }^{\circ}$ 9.613/98 (lavagem de ativos provenientes de crime). 2. ed. São Paulo: Malheiros, 2007.

MARQUES, Karla P. R. Atividade de inteligência no combate à corrupção: o papel do Ministério Público. Maceió: Edufal, 2011.

MORESI. Eduardo A. D. Monitoração ambiental e complexidade. 2001. Tese (Doutorado em Ciência da Informação) - Universidade de Brasília, 2001.

MORO, Sérgio F. Crime de Lavagem de Dinheiro. São Paulo: Saraiva, 2010.

PACHECO, Denilson F. Atividades de Inteligência e Processo Penal.

Disponível em: <http://www.advogado.adv.br/direitomilitar/ ano2005/denilsonfeitozapacheco/atividadedeinteligencia.htm>. Acesso em: 15 nov. 2010, 19:00h.

TEMPO Real - Tecnologias da Informação. Manual Analyst's Notebook 8: guia de novos recursos. Rio de Janeiro: 2010.

XU, J. J.; CHEN, H. C. Crimenet Explorer: a framework for criminal network knowledge discovery. Acm Transactions on Information Systems, n. 23, v. 2, p. 201-226, Apr. 2005.

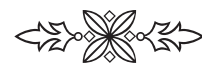

